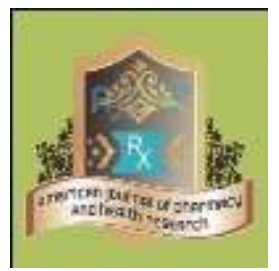

Research Article AMERICAN JOURNAL OF PHARMACY AND HEALTH RESEARCH www.ajphr.com 2018, Volume 6, Issue 04 ISSN: 2321-3647(online)

\title{
A Comparative Study of Antimicrobial Activity of Crude with Branded Medicinal Plant Oil
}

\author{
Koli PG., Murshad PM.,Tole.SB*.,Patil SM. \\ K.T. Patil College of Pharmacy, Osmanabad.
}

\begin{abstract}
For various health related problem medicinal plant oils are widely used in traditional Indian society. In present study Antimicrobial activity of different crude oils compare with standard medicinal oils. Crude oils are extracted from different parts of plants such as leaves of Eucalyptus globulus (Eucalyptus oil), Flower buds of Eugenia caryophyllus (Clove oil), Leaves of Cymbopogen citritis (Lemon grass oil), seeds of Recinus communis (Castor oil), and seed of Sesamum indicum (Sesam oil) by using Steam distillation process. The antimicrobial activity of these crude oils with standard medicinal oil was studied by disc diffusion method, against one gram +ve Bacterial species Bacillus subtilis,two gram -ve Klebsiella pneumonia \& Pseudomonas aeruginosa and one fungal strain Aspergillus niger. Comparing zone of Inhibition of crude oils with standard oils and also perform the phytochemical test for crude \& standard oils.
\end{abstract}

Keywords: Antimicrobial activity, Clevenger apparatus, Medicinal plant oil, phytochemical test 


\section{INTRODUCTION}

Medicinal plants are a rich source of antimicrobial agents. Plants are traditionally used medicinally all over the world and are a source of many potent and powerful drugs a wide range of different parts of medicinal plants are used to extract a raw drug. Which posses varied medicinal properties of the different parts such as root, stem, flower, fruits, twigs, exudeds and modified plant organs. ${ }^{(1)}$

The antimicrobial properties of essential oils have been known for many centuries. In recent years a large no. of essential oils and their constituents have been investigated for their antimicrobial properties against some bacteria and fungi. Medicinal plant oils are mostly essential oils. Essential oils are also known as volatile oils, etheral oils etc. essential oils are aromatic, oily liquid distilled from various plant parts such as flowers, buds, seeds, leaves, twigs by extraction methods such as Steam distillation, solvent extraction methods, cold pressing method. $^{(1,2)}$

Clove is an important herb due to its medicinal values people use its oils, dried flower buds, leaves and stems to prepare herbal medicines. ${ }^{(1)}$ Now a days, commercially, it is used directly to the gums for Toothache, for pain control during dental work.

Eucalyptus oil having Antiseptic abilities and used in Mosquito repellent. Lemongrass oil is used as a pesticide and preservative, it is also as an antifungal agent. lemongrass tea can be used to treat fever, cold, cough and stomach upset. The tea can also help to treat typhoid fever, blurring of vision and cancer. ${ }^{(2)}$

Castor oil having anti-inflammatory ability used in prevention of Osteoporosis, Nasal cleansing relief from Rheumatism \& Gout, Menstrual disorders, Sesam oil also have medicinal value used as an Anti-fungal and Anti- microbial. ${ }^{(1,3)}$

\section{MATERIALS AND METHOD}

\section{Microbial Strain}

The Bacterial strain such as Bacillus subtilis (Gram positive), Klebsiella pneumonia \& Pseudomonous aeruginosa (Gram negative) \& Aspergillus niger (Fungi).

\section{Chemicals}

All the chemicals and solvents used in this research work study were analytical grade. Nutrient agar plate for antimicrobial activity were obtained from the Pharmaceutical Microbiology lab of K. T. Patil College of Pharmacy, Osmanabad. Nutrient agar plate Culture Broth of each 
microbial strain extracted crude oil, standard oil, ethanol, Ferric chloride, Petroleum ether, Sodium nitrite, Glacial acetate, $1 \%$ solution of sucrose in HCL.

\section{Preparation of Inoculum}

Loop full of culture of given microbial strain from respective slants was inoculated in $5 \mathrm{ml}$ sterile nutrient broth and incubated at $37^{\circ} \mathrm{c}$ for $24 \mathrm{hrs}{ }^{(3,4)}$

\section{METHOD}

\section{Antimicrobial activity by Disc Diffusion method:}

Preparing nutrient agar plate, introduce fully growing bacterial culture broth (2-3 drops) into the Petri dish containing agar medium, then spread it in all over the plate by tilting, Make a cup-plate by using sterile metal borer. Each plate carry two cup-plates, one responses for standard oil \& another for crude oil, Fill up the cup-plate by respective standard \& crude oil, introduce the plates carefully in a refrigerator for 1 to $2 \mathrm{hrs}$ and remove the plates from refrigerator and transfer to incubator for $24 \mathrm{hrs}$ at $37^{\circ} \mathrm{c}$,for observing \& comparing the zone of inhibition. ${ }^{(4,5)}$

\section{RESULTS AND DISCUSSION}

For observing the antimicrobial activity firstly we can use bacterial strain of Bacillus subtilis. We take Eugenia caryophyllus (clove oil), Eucalyptus globulus (Eucalyptus oil), Cymbopogen citritis (Lemongrass oil), Sesamum indicum (sesam oil), Ricinus communis (castor oil) for assessing antimicrobial activity \& compare with standard oil. We check first standard concentration of crude \& standard medicinal plant oil. So we carry activity starting from $50 \mu 1$ sample of each medicinal plant.

We make two cup-plate for two different standard oil\& another for two different crude oils. Our result showing that standard sample have little antimicrobial activity but crude sample did not show antimicrobial activity against Bacillus subtilis.

In next aspect, we increase the concentration up to $75 \mu$. with same microbial strain of Bacillus subtilis. Our result showing that, the standard Sample show stronger antimicrobial activity than the crude sample.

In next aspect we increase the concentration up to $100 \mu 1$ and change the pattern of cup-plate, signal plate having two cup-plates one for std. \& another for crude of same sample. We check the antimicrobial activity, after comparing the zone of inhibition we saying that std. oils have the proportionate activity with our crude but some std. fails to come with crude. 
At $100 \mu \mathrm{l}$ we observe the increasing activity than previous concentrations then we can fix the concentration of $100 \mu 1$.We check the antimicrobial activity at $100 \mu 1$ against Klebsiellia pneumonia, Pseudomonas aeruginosa (gram-ve), \&Aspergillus niger (fungal strain).

\section{Table 1: Phytochemical test of extracted crude oil}

\begin{tabular}{|c|c|c|c|}
\hline & Oil & Test & Result \\
\hline 1 & Clove Oil & Clove oil + Ferric chloride $5 \%$ solution & $\begin{array}{l}\text { Blue coloration. (due to } \\
\text { Eugenol) })^{(2,6)}\end{array}$ \\
\hline 2 & $\begin{array}{l}\text { Eucalyptus } \\
\text { oil }\end{array}$ & $\begin{array}{l}2.5 \mathrm{ml} \text { of eucalyptus oil }+5 \mathrm{ml} \text { purified } \\
\text { petroleum benzins }+5 \mathrm{ml} \text { solution of } \\
\text { sodium nitrite }(5 \mathrm{gm} \text { sodium \& } 8 \mathrm{ml} \text { of } \\
\text { purified water). }+ \text { then add } 5 \mathrm{ml} \text { glacial } \\
\text { acetic acid }\end{array}$ & $\begin{array}{l}\text { Phellandrene nitrite do not form } \\
\text { in the mixture within } 10 \mathrm{~min} .{ }^{(2)}\end{array}$ \\
\hline 3 & Sesam oil & $\begin{array}{l}\text { Shake } 2 \mathrm{ml} \text { sesam oil with } 1 \mathrm{ml} 1 \% \\
\text { solution of sucrose in HCL. }\end{array}$ & $\begin{array}{l}\text { pink or red color is produced. } \\
{\text { (due to sesamol) }{ }^{(6)}}\end{array}$ \\
\hline
\end{tabular}

Table 2: Antimicrobial activity of Medicinal plant oil at concentration 100 $\mu \mathrm{l}$

\begin{tabular}{|c|c|c|c|c|c|c|c|c|c|c|}
\hline \multirow{2}{*}{$\begin{array}{l}\text { Oils } \\
\text { Organisms }\end{array}$} & \multicolumn{2}{|c|}{ Clove oil } & \multicolumn{2}{|c|}{ Eucalyptus oil } & \multicolumn{2}{|c|}{ Lemon grass oil } & \multicolumn{2}{|c|}{ Sesam oil } & \multicolumn{2}{|c|}{ Castor oil } \\
\hline & Std. & Crude & Std. & Crude & Std. & Crude & Std. & Crude & Std & Crude \\
\hline Bacillus subtilis & $8 \mathrm{~mm}$ & $7 \mathrm{~mm}$ & $10 \mathrm{~mm}$ & $6 \mathrm{~mm}$ & NI & NI & NI & NI & NI & NI \\
\hline Klebsiella pneumonia & $8 \mathrm{~mm}$ & $10 \mathrm{~mm}$ & NI & NI & NI & NI & $8 \mathrm{~mm}$ & $1 \mathrm{~mm}$ & NI & NI \\
\hline $\begin{array}{l}\text { Pseudomonas } \\
\text { aeruginosa }\end{array}$ & $7 \mathrm{~mm}$ & $9 \mathrm{~mm}$ & $10 \mathrm{~mm}$ & $3 \mathrm{~mm}$ & $6 \mathrm{~mm}$ & $3 \mathrm{~mm}$ & $1 \mathrm{~mm}$ & NI & NI & NI \\
\hline Aspergillus niger & $10 \mathrm{~mm}$ & $8 \mathrm{~mm}$ & $14 \mathrm{~mm}$ & $8 \mathrm{~mm}$ & NI & NI & $3 \mathrm{~mm}$ & $1 \mathrm{~mm}$ & NI & NI \\
\hline
\end{tabular}


Tole et al.,

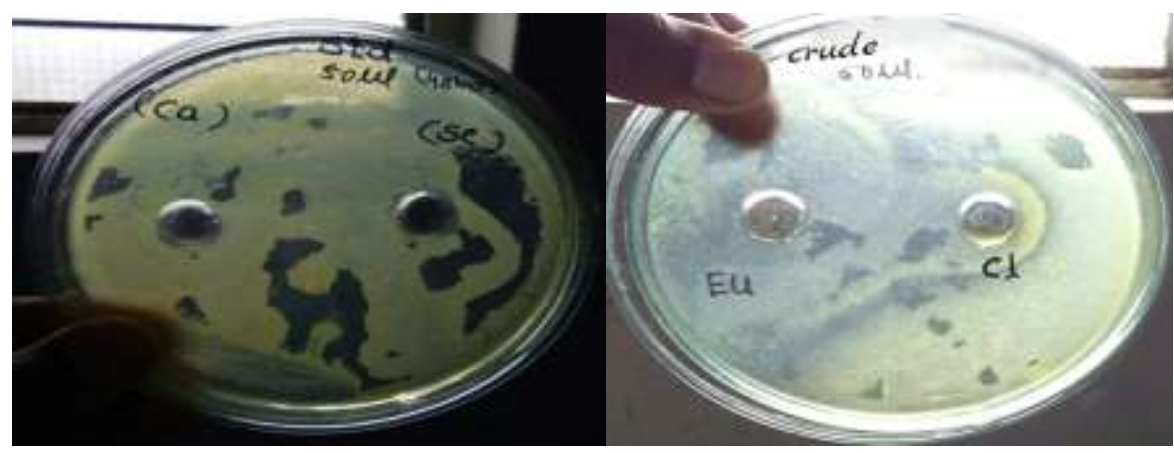

1

2

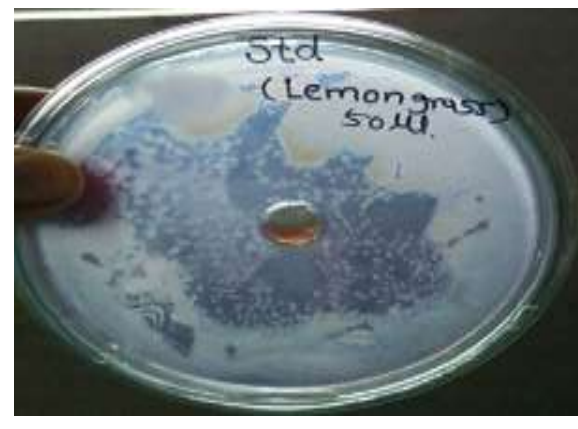

3

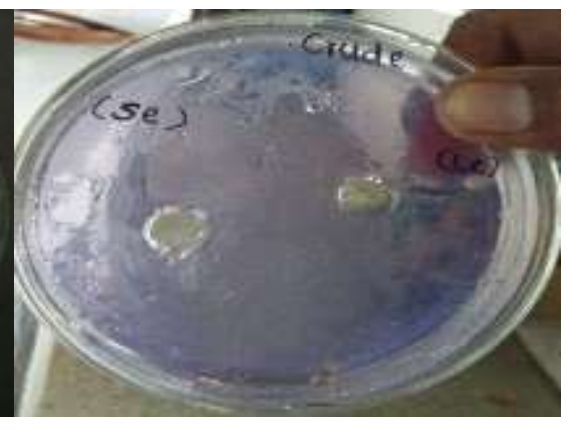

4

Figure 1: Antimicrobial activity at 50 $\mu$ l against Bacillus subtilis

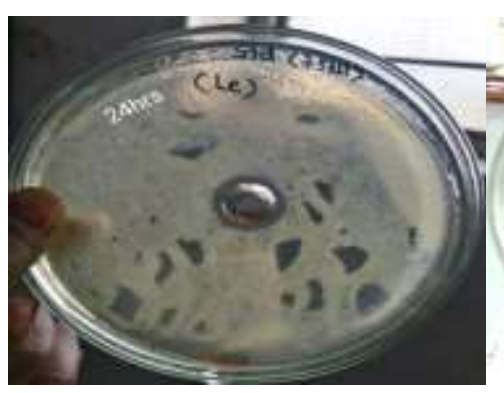

5

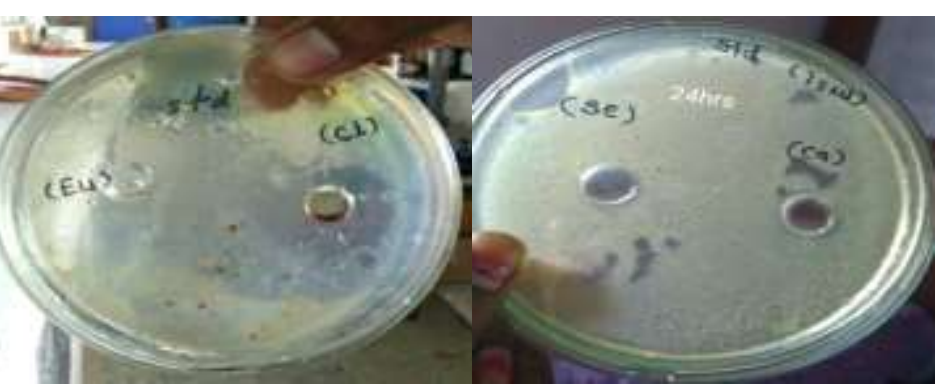

7

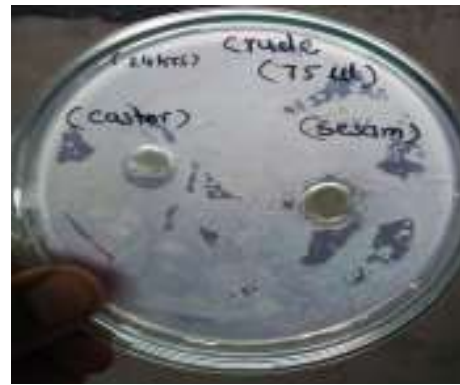

8

9

Figure 2: Antimicrobial activity at $75 \mu$ l. against Bacillus subtilis. 


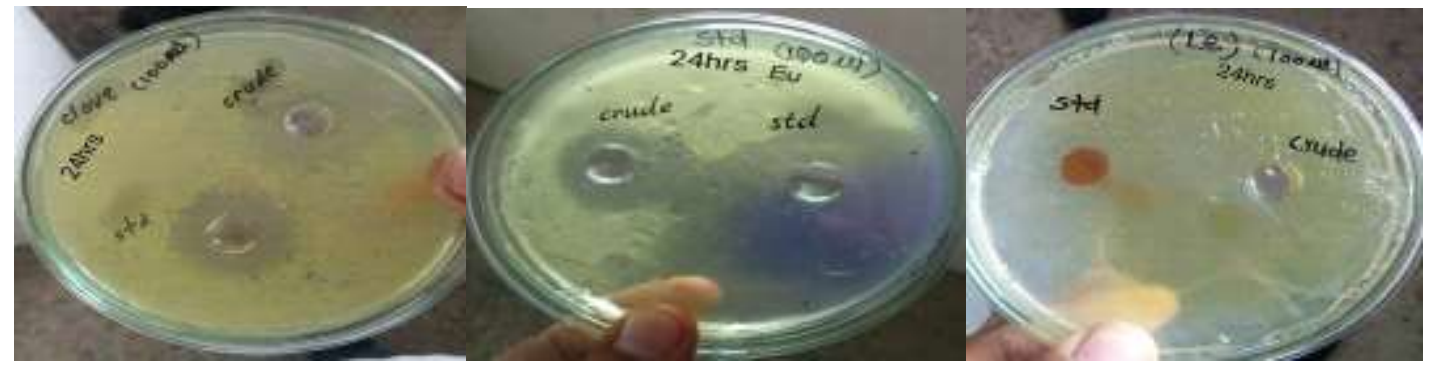

11

12

13

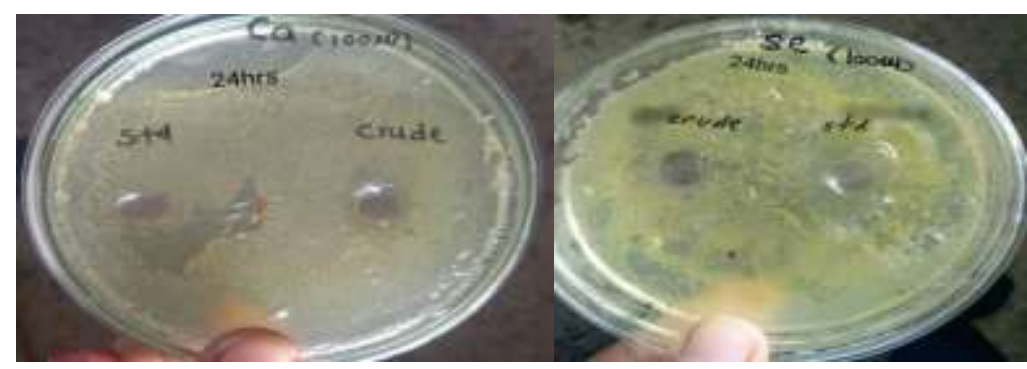

14

15

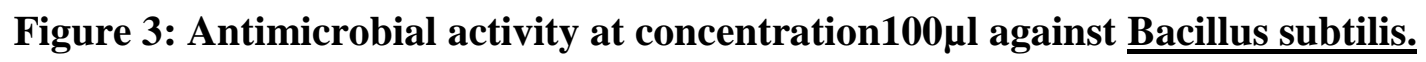

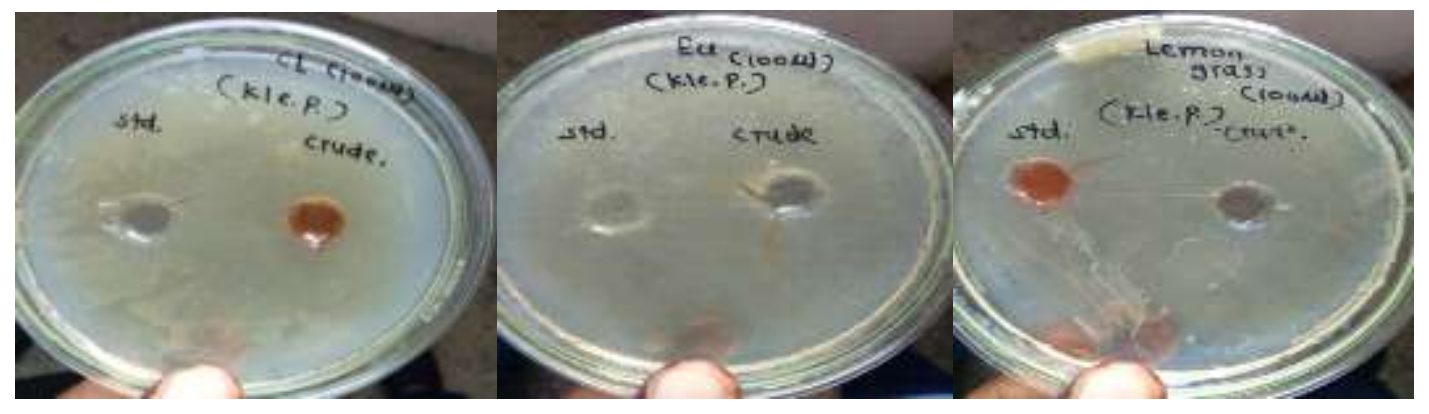

$\begin{array}{lll}16 & 17 & 18\end{array}$

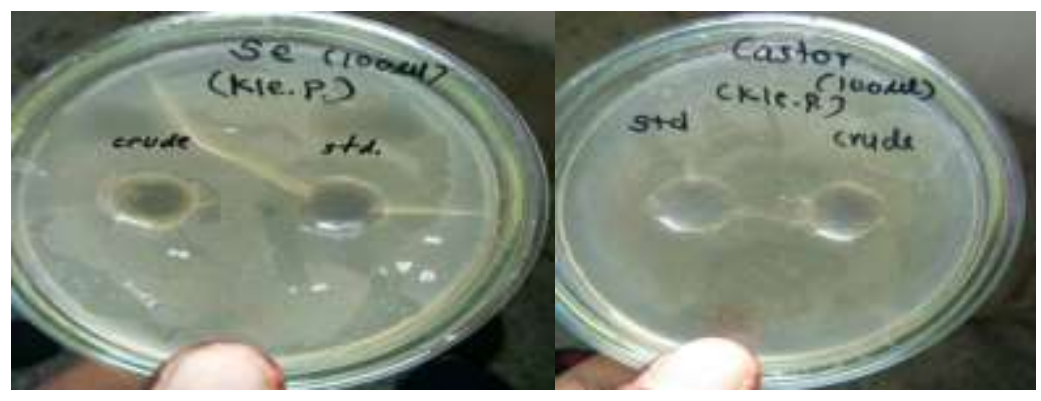

19

20

Figure 4: Antimicrobial activity at $100 \mu \mathrm{l}$ against Klebsiella pneumonia. 
Tole et al., Am. J. Pharm Health Res 2018;6(04) ISSN: 2321-3647

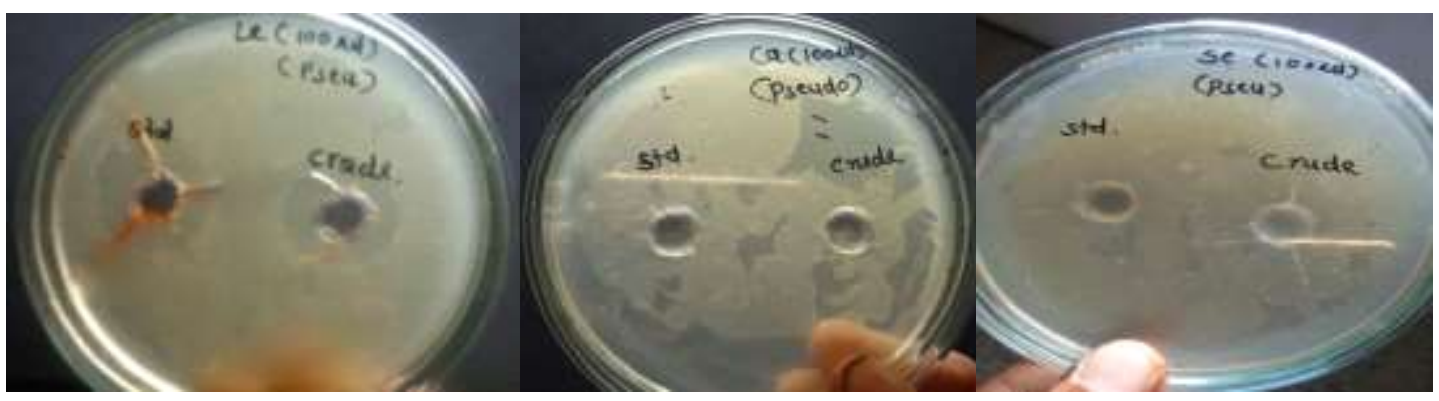

21

22

23

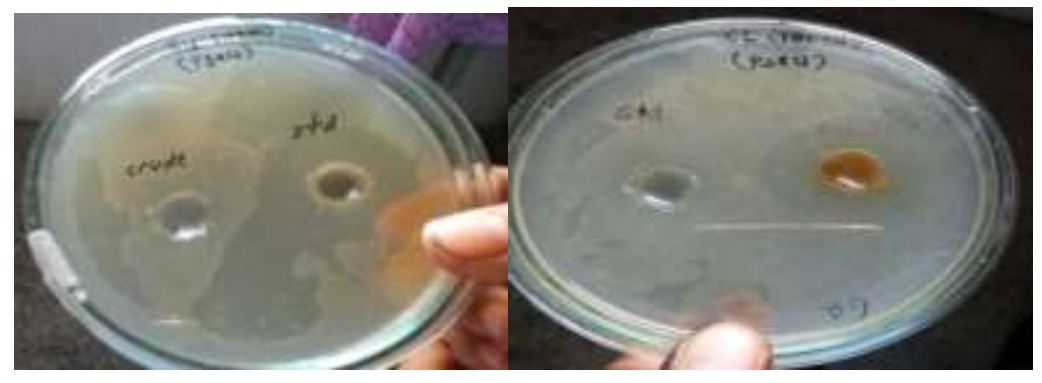

24

25

Figure 5: Antimicrobial activity at 100 $\mu$ l against Pseudomonas aeruginosa.

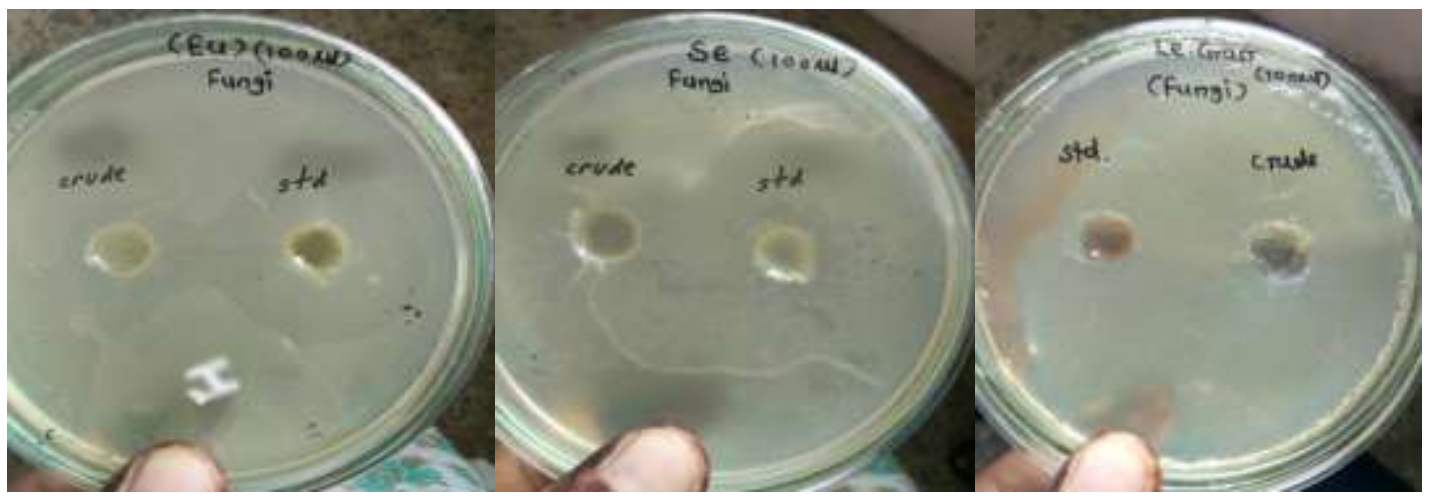

26

27

28

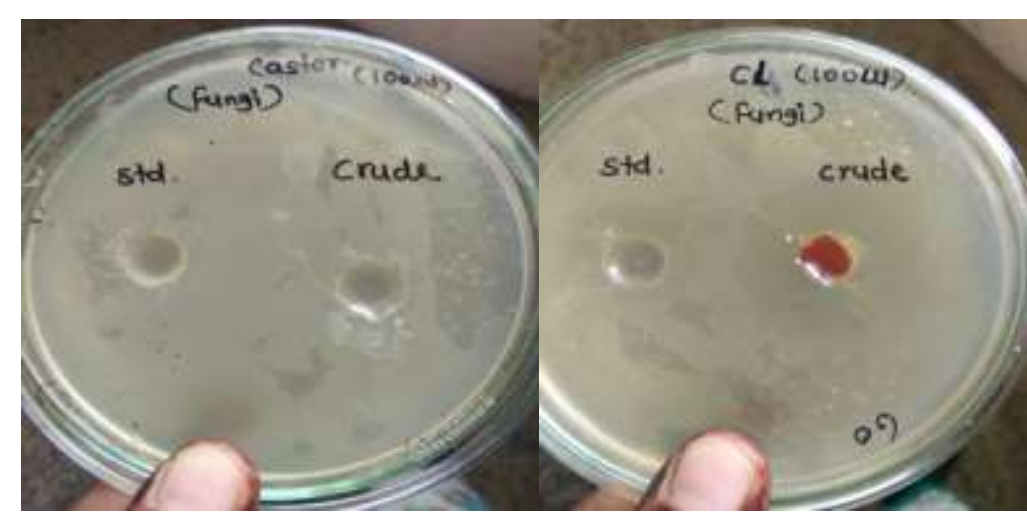

29

30

Figure 6: Antimicrobial activity at $100 \mu \mathrm{l}$ against Aspergillus niger. 


\section{CONCLUSION}

From the above work we conclude that:- $100 \mu l$ is the sufficient concentration for showing the good antimicrobial activity against Bacillus subtilis (gram+ve), Klebesiellia pneumonia, Pseudomonas aeruginosa (gram -ve) \& Aspergillus niger (Fungi)._The standard oils have the stronger activity than our crude oil but some standard fails to come with crude.

\section{REFERENCES}

1. Dr.A.M. Deshmukh, Dr. Ms J.D. Jawalikar, Dr. S.S. Waghmare, Advances in Biotech, Education Book Publisher \& Distributor, Gokulwadi, Aurangabad-431 001.

2. C.K.Kokate, A.P.Purohit, S.B. Gokhle. A book of pharmacognosy, Volume 1\&2,Forty seventh edition, Nirali Prakashan,Pune-1.20.

3. Uzama Danlami, Ahmadu Rebecca, David BwaiMachan and Thomas Sunday Asuquo, Chemistry Advanced, Sheda Science and Technology Complex, P M B 186, Garki, Abuja, Nigera.

4. Mohammad Amzad Hassain, Saliha Rashid AL Harbi, Afaf Mohammad Weli, Qasim AlRiyami, Jamal Nasser Al- Sabahi, School of Pharmacy, College of Pharmacy \& Nursing, University of Nizwa, P. O. box 33,Postal code 616, Nizwa, sultanate of Oman. Page no. 262 to 264 .

5. Shabnam Javed, Sabiamshtaq, Ibatsamkhokhar, Institute of Agriculture .university of the punjab ,Quaid-eAzam campus,Lahore-54590 Pakistan.

6. Dr. K. R .Khandelwal, Practical Pharmacognosy. Techniques \& experiments, twenty second edition ,Nirali Prakashan ,Pune page no -27.7-27.16

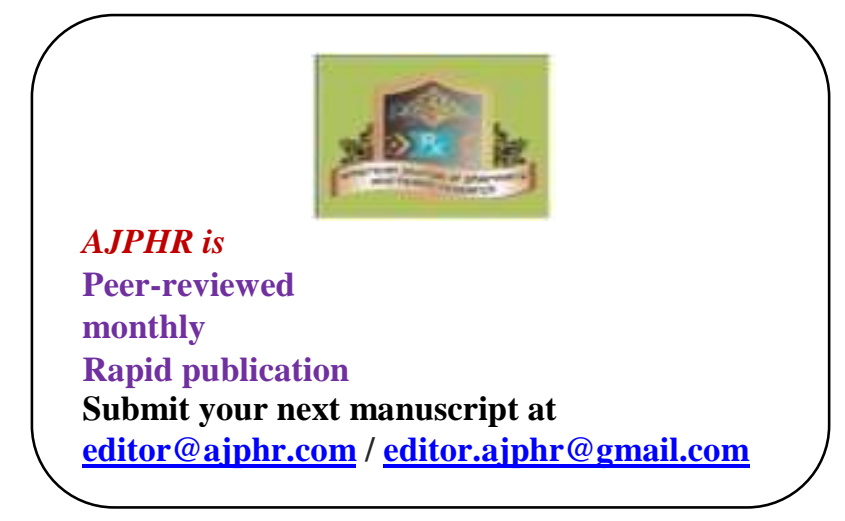

